\title{
Experimentally confirmed toltrazuril resistance in a field isolate of Cystoisospora suis
}

\author{
Aruna Shrestha ${ }^{1 \dagger}$, Barbara Freudenschuss $^{1 \dagger}$, Rutger Jansen², Barbara Hinney ${ }^{1}$, Bärbel Ruttkowski ${ }^{1}$ \\ and Anja Joachim ${ }^{1 *}$
}

\begin{abstract}
Background: Constant treatment regimens with toltrazuril against Cystoisospora suis infection in piglets are being applied in the intensive production systems for the last two decades, but the possibility of resistance development has not been addressed so far despite limited availability of treatment alternatives. Recently, a pig producer in The Netherlands who routinely used toltrazuril complained about diarrhea in suckling piglets in the absence of bacterial and viral pathogens, and oocysts of $C$. suis could be isolated from feces of affected litters.

Methods: Piglets from two litters were infected with a field isolate of C. suis, Holland-I, and treated with 0 (Holl-Ctrl), 20 (Holl-20) or 30 (Holl-30) mg/kg of body weight (BW) of toltrazuril (Baycox ${ }^{\oplus}$ ). The efficacy of toltrazuril was measured by assessment of oocyst excretion, fecal consistency and BW gain. A separate litter was infected with a toltrazurilsusceptible strain of C. suis, Wien-I, and treated with 0 (Wien-Ctrl) or 20 (Wien-20) mg/kg BW of toltrazuril for comparison.

Results: Treatment with the recommended $(20 \mathrm{mg} / \mathrm{kg}$ ) dose of toltrazuril completely suppressed oocyst shedding and diarrhea in group Wien-20. The prevalence of oocyst excretion was 100\% in the groups infected with Holland-I and 80\% in the group Wien-Ctrl. Most days with diarrhea were observed in group Holl-20 with an average of $6.40 \%$, followed by $5.71 \%$ in Wien-Ctrl, while in Holl-Ctrl and Holl-30 diarrhea was only seen in 1.79\% of the samples ( $n=14 /$ piglet). Oocyst excretion, fecal consistency and BW gain did not differ significantly among groups infected with Holland-I, indicating loss of efficacy to toltrazuril.

Conclusion: Experimental infections and treatment confirmed toltrazuril resistance against the field isolate even at increased dosage. Such isolates are a potential threat to pig production as no other effective and economically sustainable alternative treatment is currently available. In the absence of a standardized protocol for resistance testing in C. suis, regular parasitological examination and, if possible, experimental confirmation should be considered to evaluate the extent and consequences of toltrazuril resistance.
\end{abstract}

Keywords: Efficacy, Toltrazuril, Field isolate, Oocyst excretion, Pig

\section{Background}

Coccidiosis is a major parasitic disease affecting a wide range of livestock and wild animals globally. In pigs, Cystoisospora suis (syn. Isospora suis) is the most pathogenic species of swine coccidian and most severely affects suckling piglets [1-4]. Clinical signs include pasty to

\footnotetext{
* Correspondence: Anja.Joachim@vetmeduni.ac.at

${ }^{\dagger}$ Equal contributors

'Institute of Parasitology, Department of Pathobiology, University of

Veterinary Medicine Vienna, Vienna, Austria

Full list of author information is available at the end of the article
}

watery non-hemorrhagic diarrhea, weight loss and ill thrift [5-10]. At present, cystoisosporosis is considered as one of the leading causes of diarrhea in neonatal piglets with high prevalences worldwide [3, 7, 11-14]. Oocysts are highly resistant to desiccation and antimicrobial compounds $[14,15]$ making elimination virtually impossible once they have been introduced into the farm. The disease shows a very high morbidity with low mortality, and not all the piglets in a litter are equally affected, resulting in reduced, uneven weaning weights and thus, ultimately in often significant economic losses [5, 11, 16, 17]. 
In the European Union (EU), control of cystoisosporosis is commonly achieved with a single oral administration of toltrazuril in the prepatent period (day 3-5 of life). Baycox ${ }^{\circ}$ is the trade name of a broad spectrum anticoccidial drug containing the triazine trione toltrazuril [18]. Use of Baycox ${ }^{\circ}$ in piglet coccidiosis was first authorized in Australia in 1998 to be administered once in the first week of life at a dose of $20 \mathrm{mg} / \mathrm{kg}$ body weight (BW) [19]. A single oral treatment with toltrazuril administered during the prepatent period provided effective and sustained suppression of oocyst shedding and diarrhea in piglets experimentally infected with $C$. suis [17, 20-22] and under field conditions [23-28]. However, emerging resistance in poultry coccidia against anticoccidials including toltrazuril is of growing concern [29-31]. Constant treatment regimens with toltrazuril have been applied for controlling porcine cystoisosporosis in the EU for almost two decades now, but the possibility of resistance development in C. suis isolates has not been addressed so far, despite limited availability of treatment alternatives. In 2014, a pig farmer in The Netherlands, with a farrow-to-finish herd of 330 sows, complained about pasty feces in $60 \%$ of the piglets from 10 days of age until weaning despite treatment with the recommended dose of toltrazuril. The involvement of bacterial and viral pathogens was excluded as the possible pathogens associated with piglets' diarrhea could neither be re-isolated nor be detected by polymerase chain reaction (PCR). Presence of villous atrophy and fusion in the histological sections of jejunum indicated cystoisosporosis [32, 33], which was later confirmed by the detection and isolation of $C$. suis oocysts in the fecal samples. Evaluation of the administered amount of toltrazuril on the farm level revealed no under-dosing. Moreover, application of twice the recommended dose $(40 \mathrm{mg} / \mathrm{kg}$ ) of toltrazuril also did not have any effect on the clinical picture and thus loss of efficacy was suspected. In the present study, the efficacy of toltrazuril against $C$. suis infections in suckling piglets was evaluated in experimental infections with the mentioned field isolate, Holland-I, and a toltrazuril-sensitive strain, Wien-I. In the past, experimental studies have indicated development of resistance under field conditions in Eimeria of poultry [34-36]. To our knowledge, this is the first report of experimentally confirmed toltrazuril resistance in a field isolate of $C$. suis.

\section{Methods}

\section{Study animals}

A total of 34 conventionally raised healthy piglets from three crossbred sows (Landrace $\times$ Large White) were allotted to five treatment groups (Table 1). Sows were housed on straw in individual farrowing crates in the animal husbandry facility of the Institute of Parasitology,
University of Veterinary Medicine Vienna, Austria. All rooms were equipped with daylight and ventilation, and room temperature of $18-20{ }^{\circ} \mathrm{C}$ was maintained throughout the trial. Fresh drinking water was provided ad libitum to the sows and piglets. The sows were fed once daily with a commercial feed without coccidiostat according to the manufacturer's recommendation and the piglets received milk from the sow followed by starter feed from the second week of life. The day of birth of piglets was considered as study day 1 (SD 1). All piglets were ear-marked and received $100 \mathrm{mg}$ iron dextran on SD 2 to prevent iron deficiency. The sows arrived two weeks prior to the expected parturition date for adaptation to the new environment.

\section{Study design}

The clinical trial followed a blinded and incompletely randomized block design consisting of two blocks (one for each C. suis strain), each containing the control and the treatment group(s). The experimental unit was the individual animal. Randomization was carried out in each block assigning piglets to the respective treatment group ( $n=5$ to 8 piglets/group), ranking animals based on decreasing birth weight. The animals were distributed among the litters as described in Table 1.

\section{Parasite material and experimental infection}

Oocysts of the Holland-I field isolate of $C$. suis were obtained from fecal samples originating from the mentioned commercial farm in The Netherlands with suspected reduced sensitivity to toltrazuril. Before performing resistance studies the field isolate was passaged once through piglets for collection of fresh, viable oocysts. A toltrazuril-sensitive strain of C. suis, Wien-I [20], was used for comparison between the strains which was maintained and passaged regularly in suckling piglets for the production of infectious oocysts at the Institute of Parasitology, University of Veterinary Medicine Vienna, Austria. The strain is passaged every 3-6 months and infectivity in vivo and susceptibility to toltrazuril are assessed regularly. Each piglet was inoculated orally with 1000 C. suis oocysts, suspended in $1 \mathrm{ml}$ of tap water, of the respective C. suis strain on SD 4 using a flexible plastic Pasteur pipette. The groups were denominated on the basis of treatment (Table 1) on SD 6 and received either sham-treatment or a commercial formulation of toltrazuril (Baycox ${ }^{\circ} 5 \%$ oral suspension; Batch no: KPOBFX9; Expiry date: 06/2021, Leverkusen, Germany). Animals infected with Wien-I received the recommended dose of $20 \mathrm{mg} / \mathrm{kg}$ of body weight (BW) of toltrazuril (Wien-20). Piglets infected with Holland-I were treated with $20 \mathrm{mg} / \mathrm{kg} \mathrm{BW}$ (Holl20) or an elevated dose of $30 \mathrm{mg} / \mathrm{kg} \mathrm{BW}$ (Holl-30) of toltrazuril. Piglets in the sham-treated control groups 
Table 1 Groups, infections and treatment in the trial. Infection: study day 4; treatment: toltrazuril (Baycox ${ }^{\circledR}$ 5\% suspension for piglets) once on study day 6

\begin{tabular}{|c|c|c|c|c|}
\hline Group & C. suis strain & Litter no. & Treatment/Dose & No. of piglets \\
\hline Wien-Ctrl & Wien-I & 1 & Tap water; $1 \mathrm{ml}$ & 5 \\
\hline Wien-20 & Wien-I & 1 & Toltrazuril; 20 mg/kg body weight & 5 \\
\hline \multirow[t]{2}{*}{ Holl-Ctrl } & Holland-I & 2 & Tap water; $1 \mathrm{ml}$ & 4 \\
\hline & & 3 & & 4 \\
\hline \multirow[t]{2}{*}{ Holl-20 } & Holland-I & 2 & Toltrazuril; 20 mg/kg body weight & 4 \\
\hline & & 3 & & 4 \\
\hline \multirow[t]{2}{*}{ Holl-30 } & Holland-I & 2 & Toltrazuril; 30 mg/kg body weight & 4 \\
\hline & & 3 & & 4 \\
\hline
\end{tabular}

(Wien-Ctrl and Holl-Ctrl) received $1 \mathrm{ml}$ of tap water orally. The efficacy of toltrazuril was evaluated by assessment of body weight development, fecal consistency and oocyst excretion.

\section{Evaluation of fecal samples}

Individual fecal samples were collected daily from SD 8 to 21 for the evaluation of fecal consistency and oocyst excretion. Fecal consistency was scored immediately after sampling according to the following key: fecal score (FS) 1 =normal; FS 2 = pasty; FS $3=$ semi-liquid; and FS $4=$ liquid, with FS 3 and FS 4 considered as diarrhea [7]. Fecal samples were first screened for oocysts by autofluorescence (AF) detection under UV light [37] with a sensitivity of ca. $10 \mathrm{OpG}$; in positive samples oocyst excretion was determined quantitatively using a modified McMaster technique [3].

\section{Body weight and general health observation}

The piglets were weighed on SD 1, 8, 15 and 22. Additionally, the body weight of each piglet was recorded on the day of treatment for calculation of the treatment dose. All piglets were observed daily during the course of the studies to ensure good general health and any condition that required veterinary care was recorded and addressed.

\section{Differential diagnosis}

Pooled fecal samples of each litter were screened on SD 8 for the presence of any other pathogens causing diarrhea in neonatal piglets including rotavirus, coronavirus, E. coli and C. perfringens.

\section{Statistical analysis}

Statistical calculations were performed with RStudio version 0.99.896 (RStudio Team, 2016), descriptive statistics with Microsoft Excel 2010 and GraphPad Prism version 5.04 for Windows (GraphPad Software, San Diego, California USA). Differences in clinical and parasitological parameters between groups were analyzed applying an ANOVA in case of normal distribution and variance homogeneity of the data, or a Kruskal-Wallis rank sum test if this was not the case. In the event of significance for the omnibus tests parametric or nonparametric post-hoc tests for multiple comparisons were performed (according to Tukey and Conover, respectively), using $P$-value adjustment after Bonferroni. Statistical calculations were restricted to groups Holl-Ctrl, Holl-20 and Holl-30 ( $n=8$ animals/group) due to the small size of groups Wien-Ctrl and Wien-20 $(n=5$ animals/group). Spearman's rank correlation coefficient was calculated to describe the relationship between selected parameters. $P$-values $\leq 0.05$ were considered significant.

\section{Results}

\section{Oocyst excretion}

Excretion of $C$. suis oocysts was completely suppressed by the treatment in group Wien-20 while all other groups excreted oocysts detectable in AF (Fig. 1) and McMaster (Table 2) techniques. Oocyst shedding was first observed in these groups on SD 9, and by SD 12 all animals except one had been positive at least once (Fig. 2). In groups Holl-Ctrl, Holl-20 and Holl-30 every piglet excreted oocysts at least once, whereas in group Wien-Ctrl all piglets except one shed oocysts (Table 2). The prevalence in piglets infected with Holland-I peaked on SD 11 with $87.5 \%$ positive piglets in group Holl-Ctrl and $100 \%$ positive piglets in groups Holl-20 and Holl-30. In group Wien-Ctrl the prevalence reached its maximum (80\%) on SD 12 (Fig. 1). Prepatency tended to be shorter in piglets infected with Holland-I (Table 2). The number of excretion days (AF) was similar in all groups with excretion, ranging from 30.0 to $38.4 \%$ of all sampling days in the different groups (Table 2).

The highest individual oocyst shedding (max OpG) was seen in group Holl-Ctrl on SD 14. Generally, max OpGs were higher in groups infected with the Holland-I isolate (Table 2). Oocyst excretion reached its peak on SD 11-12 (Fig. 3), and was most pronounced in group 


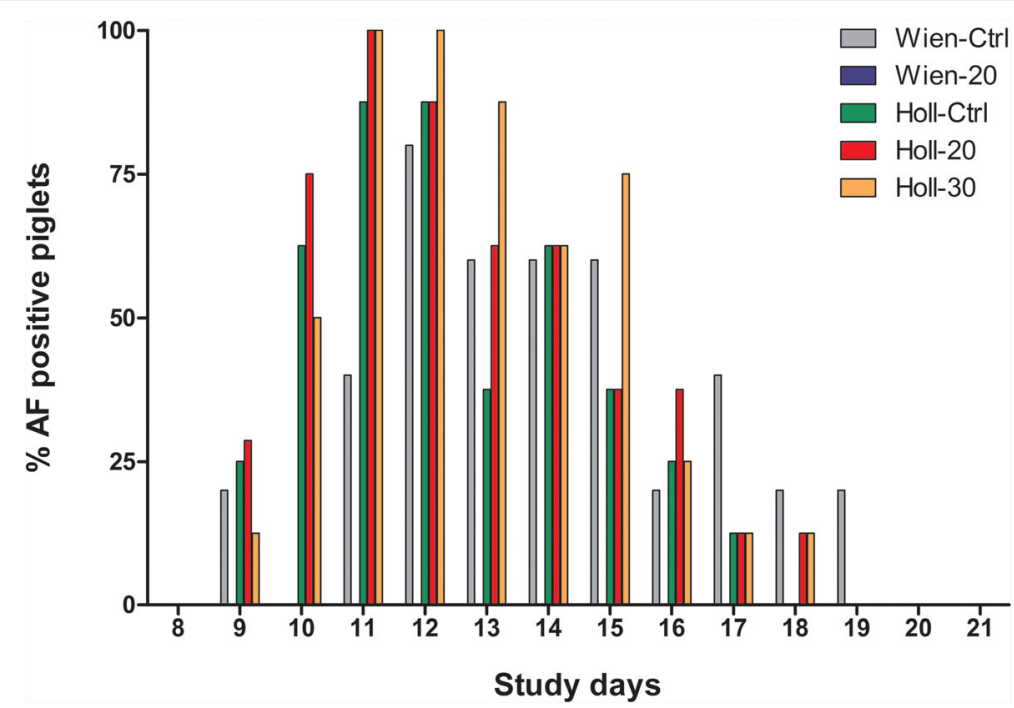

Fig. 1 Percentage of C. suis positive piglets on the respective study days as detected by fluorescence microscopy

Holl-30 with a mean OpG value of 196,803. The amount of shed oocysts exhibited high variabilities between individuals, ranging from 333 to 365,301 within the same group, without significant differences in daily mean OpG values, the area under the curve (AUC) for OpG SD 9 to 19 as well as the mean OpG SD 9 to 19 between groups infected with Holland-I.

\section{Fecal consistency and diarrhea}

None of the study animals had diarrhea on the day of infection. Moreover, the mean fecal score of Wien-20 did not exceed 1.20 throughout the study. The mean FS reached its peak on SD 13 in groups Wien-Ctrl, HollCtrl and Holl-30 with 2.80, 2.13 and 2.00, respectively, and with 2.25 on SD 12 in group Holl-20 (Fig. 4). Neither the overall mean FS from SD 9 to 18 (Table 3) nor the mean FS on single study days differed significantly between groups infected with Holland-I.

Diarrhea was not observed at all in group Wien-20. The prevalence of diarrhea peaked on SD 13 in groups Wien-Ctrl and Holl-Ctrl with 60 and 25\% of the piglets having FS $>2$, respectively. In group Holl-20, the prevalence reached its maximum already on SD 9 (28.57\%) and on SDs 12 and 13 in group Holl-30 with 12.5\% each. Most days with diarrhea were observed in group Holl-20 with an average of $6.40 \%$, followed by $5.71 \%$ in group Wien-Ctrl, while in groups Holl-Ctrl and Holl-30 diarrhea was only seen in $1.79 \%$ of the samples. Percentage of piglets with $\mathrm{FS}>2$ at least once ranged from $12.5 \%$ (Holl-30) to 62.5\% (Holl-20) (Table 3). However, the number of diarrhea days and piglets that had diarrhea at least once did not differ significantly between groups infected with Holland-I. FS 4 (watery) was only observed in two piglets of group Wien-Ctrl on SD 13.

\section{Body weight}

Since the birth weight of two individual piglets was below $0.9 \mathrm{~kg}$, they were excluded from the body weight calculation. Mean body weights and mean body weight gains (baseline: SD1) did not differ significantly $(P>0.05)$ between groups Holl-Ctrl, Holl-20 and Holl-30 throughout the study (Additional file 1: Table S1) although a

Table 2 Overview of the parasitological parameters (AF and McMaster countable excretion) for all experimental groups

\begin{tabular}{|c|c|c|c|c|c|c|c|c|c|}
\hline Group & $\begin{array}{l}\% \text { piglets } \\
\text { with oocyst } \\
\text { excretion }\end{array}$ & $\begin{array}{l}\text { Mean } \pm \text { SD } \\
\text { excretion } \\
\text { days/piglet }\end{array}$ & $\begin{array}{l}\text { \% excretion days } \pm \text { SD } \\
\text { (14 sampling } \\
\text { days/piglet) }\end{array}$ & $\begin{array}{l}\% \text { days with } \\
\text { McMaster } \\
\text { countable excretion } \pm S D\end{array}$ & $\begin{array}{l}\text { Mean } \pm \text { SD } \\
\text { prepatency } \\
\text { (days) }\end{array}$ & $\begin{array}{l}\text { Mean AUC } \\
\text { Study days 9-19 }\end{array}$ & $\begin{array}{l}\text { Mean } \pm \text { SD } \\
\text { OpG Study } \\
\text { days 9-19 }\end{array}$ & $\begin{array}{l}\text { Median } \\
\text { OpG Study } \\
\text { days 9-19 }\end{array}$ & $\begin{array}{l}\text { Max OpG } \\
\text { (Study day) }\end{array}$ \\
\hline Wien-Ctrl & 80 & $4.2 \pm 3.0$ & $30.0 \pm 21.1$ & $27.1 \pm 23.4$ & $7.0 \pm 1.4$ & $8,892.8$ & $12,902.2 \pm 12,950.8$ & $2,997.0$ & $97,236(11)$ \\
\hline Wien-20 & 0 & 0 & 0 & - & - & - & - & - & - \\
\hline Holl-Ctrl & 100 & $4.4 \pm 2.1$ & $31.3 \pm 15.2$ & $25.9 \pm 14.8$ & $6.3 \pm 1.0$ & $16,444.8$ & $23,169.9 \pm 29,227.4$ & 666.0 & $365,301(14)$ \\
\hline Holl-20 & 100 & $5.0 \pm 1.8$ & $36.3 \pm 12.4$ & $23.4 \pm 15.0$ & $6.0 \pm 0.8$ & $19,450.9$ & $21,723.1 \pm 21,261.8$ & $1,332.0$ & $166,500(9)$ \\
\hline Holl-30 & 100 & $5.4 \pm 1.9$ & $38.4 \pm 13.2$ & $32.1 \pm 15.3$ & $6.4 \pm 0.7$ & $22,193.6$ & $18,976.4 \pm 15,221.2$ & $1,998.0$ & $196,803(9)$ \\
\hline
\end{tabular}

For parameters related to quantitative excretion, only the period with observed McMaster counts was evaluated Abbreviations: AUC area under the curve for OpG (oocysts per gram of feces), SD standard deviation 


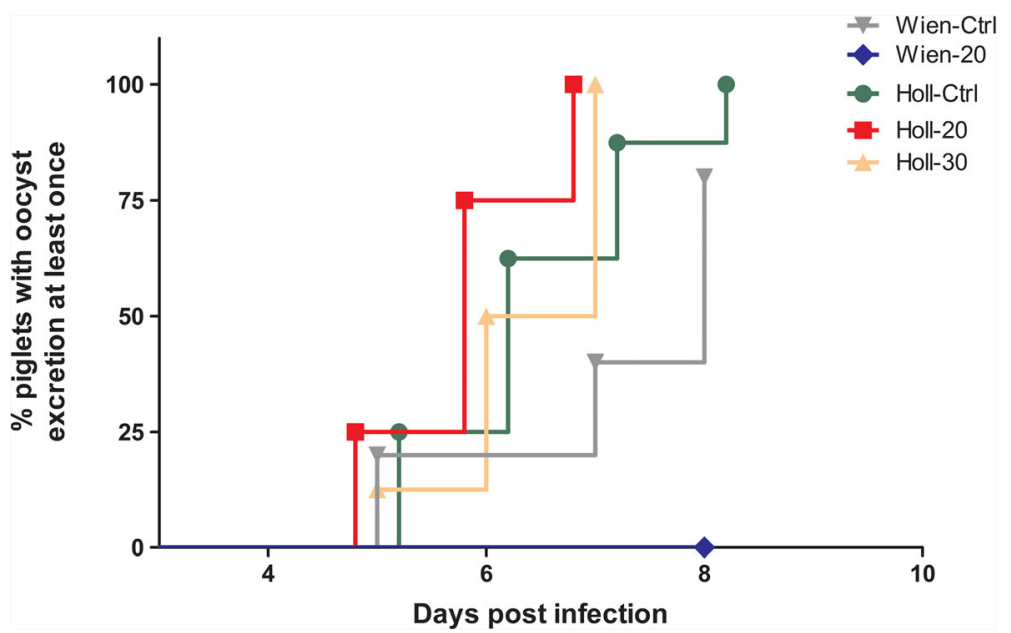

Fig. 2 Percentage of piglets with oocyst excretion at least once post-infection as detected by fluorescence microscopy

significant negative correlation between the mean fecal score and the individual weight gain from SD 1 to 22 was observed for all included animals $(\rho=-0.486, P=0.005)$.

\section{Differential diagnosis}

Fecal samples pooled by litter on SD 8 tested negative for rotavirus and coronavirus while $E$. coli as well as $C$. perfringens could be isolated from all litters.

\section{General health}

Piglets showed softened feces (FS 2) or diarrhea (FS 3 or 4) as described. No condition related to the experimental infection requiring veterinary treatment was observed.

\section{Discussion}

Resistance to all classes of anticoccidials is well described in avian coccidia [30, 38, 39]. Despite the longterm use of toltrazuril in piglet production and the lack of satisfying treatment alternatives, the possibility of resistance development has not been addressed so far. In the present study we evaluated the efficacy of toltrazuril against a C. suis isolate from a Dutch farm complaining about symptoms typical of coccidiosis despite metaphylactic treatment with the recommended dose of toltrazuril. In an experimental setup, two litters were infected with the isolate in question and treated with 0,20 or $30 \mathrm{mg} / \mathrm{kg} \mathrm{BW}$ of toltrazuril. Additionally, a third litter was infected with a toltrazuril-sensitive strain (Wien-I) and treated with $20 \mathrm{mg} / \mathrm{kg}$ BW of toltrazuril or sham

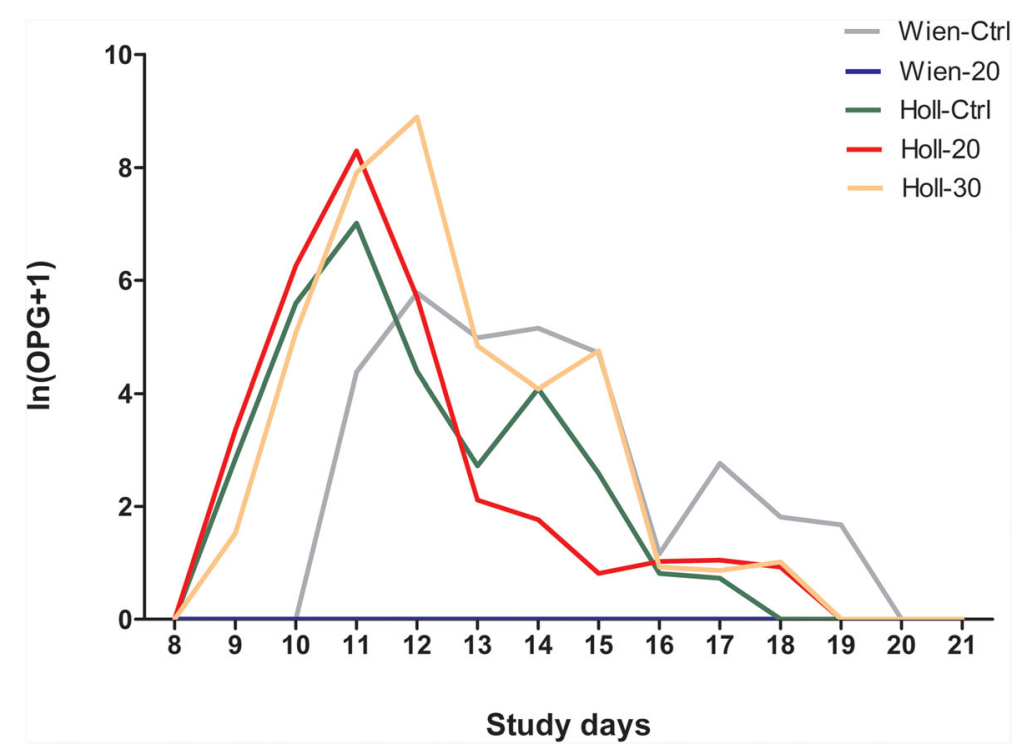

Fig. 3 Daily oocyst excretion $(\ln (\mathrm{OpG}+1))$ in piglets from study days 8-21 as determined by McMaster technique 


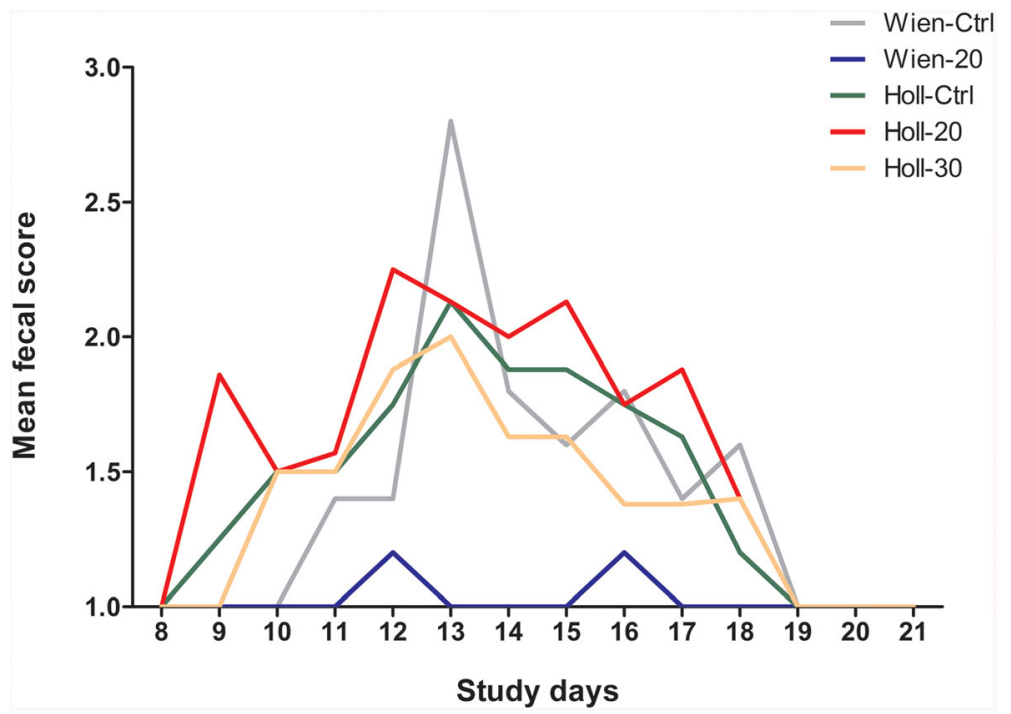

Fig. 4 Mean fecal scores of piglets throughout the sampling period (study days 8-21)

treated to confirm effectiveness of the Baycox ${ }^{\circ}$ batch used. Due to animal welfare reasons only a minimum number of animals were infected with this strain; therefore, statistics could not be employed for these groups. However, the positive effect of toltrazuril on oocyst excretion, fecal score and body weight gain was sufficiently shown in several earlier field and experimental studies [7, 17, 20, 21, 24, 26, 40, 41]. It completely inhibits the development of all parasitic stages of $C$. suis and, given during the prepatent period of infection, prevents tissue damage and consequently the emergence of diarrhea [42].

Resistance is described by the World Health Organization [43] as the "ability of a parasite strain to survive and/or multiply despite the administration and absorption of a drug given in doses equal to or higher than those usually recommended but within tolerance of the subject". This definition can also be employed for coccidia. The reliability of toltrazuril to significantly reduce the excretion of $C$. suis oocysts was already shown in a number of experimental studies [20, 21, 41, 42]. Mundt et al. [7] described a complete suppression of oocyst shedding in experimentally infected and toltrazuriltreated animals while every untreated animal shed parasites at least once. In another study conducted by Mundt et al. [17], the treatment with toltrazuril resulted in significantly fewer mean excretion days (0.6 vs 4.0), fewer piglets with oocyst excretion (30 vs 91\%) and a significantly lower mean OpG (144 vs 17,797) 5 to 11 days post-infection (dpi). This is in accordance to a field study conducted by Kreiner et al. [24] where the number of $C$. suis positive samples was significantly lower in toltrazuril-treated compared to untreated piglets in different herds. The same effect was observed in this study for group Wien-20, where oocyst shedding was completely suppressed by the treatment. By contrast, treatment with toltrazuril did not impair oocyst development and excretion in the groups infected with the Dutch isolate, Holland-I. In avian coccidiosis complete drug resistance is defined by ineffectiveness despite higher doses [44]. Every single piglet infected with the Holland-I isolate shed oocysts regardless of the toltrazuril dose. Moreover, the number of $\mathrm{AF}$ countable excretion days, the AUC for OpG, the maximum individual OpG as well as the mean OpG from SD 9 to 19 was comparable between the control and treatment groups of this isolate, indicating complete drug resistance. The above mentioned parameters

Table 3 Clinical parameters in the forms of fecal consistency and intensity of diarrhea in all experimental groups over the study period

\begin{tabular}{llll}
\hline Group & \% piglets with diarrhea at least once & \% diarrhea days \pm SD (14 sampling days/piglet) & Mean \pm SD fecal score (study days 9-18) \\
\hline Wien-Ctrl & 60.0 & $5.7 \pm 6.0$ & $1.6 \pm 0.4$ \\
Wien-20 & 0 & 0 & $1.0 \pm 0.1$ \\
Holl-Ctrl & 25.0 & $1.8 \pm 3.3$ & $1.7 \pm 0.4$ \\
Holl-20 & 62.5 & $6.4 \pm 6.0$ & $1.9 \pm 0.3$ \\
Holl-30 & 12.5 & $1.8 \pm 5.1$ & $1.5 \pm 0.3$
\end{tabular}

For quantitative evaluation of the fecal score only the period of mean values $>1.00$ was evaluated for study days $9-18$ 
tended to be higher in groups Holl-Ctrl, Holl-20 and Holl-30 compared to group Wien-Ctrl, and the prepatent period for excretion detected by AF technique was shorter in Holland-I compared to Wien-I. Variations in prepatent periods can be attributed not only to factors such as infection dose or age and health of piglets (which were comparable between all groups) but also to the virulence of $C$. suis isolates $[7,45,46]$. However, as oocyst excretion underlies large individual variations [7, 47-49] reliable conclusions about possible differences between strains regarding this particular trait cannot be drawn at this point in time.

While mean fecal consistencies remained below 1.2 in group Wien-20, all other groups developed increased mean fecal scores after infection, indicating enteritis as a consequence of parasite replication [50]. Diarrhea was observed in all groups except group Wien-20, but prevalences and numbers of diarrhea days were generally low. It has been previously shown that toltrazuril successfully reduces fecal scores and suppresses diarrhea in piglets infected with $C$. suis [17, 41, 42, 51]. In a field study, Scala et al. [26] found the overall diarrhea prevalence to be significantly lower in toltrazuril-treated animals compared to untreated animals. Similarly, Kreiner et al. [24] found treated animals to have a significantly lower mean FS and significantly fewer diarrheic fecal samples in the field. In two trials conducted by Joachim \& Mundt [20] not a single piglet with diarrhea was observed after treatment with toltrazuril while almost all untreated animals had a FS of 3 or 4 (85.7 and $100 \%$, respectively) at least once. This was also described by Mundt et al. [7] who observed an average FS of 2 or more in experimentally infected piglets throughout the study, with daily diarrhea prevalences between 25 and $75 \%$. On the other hand, the mean FS of animals treated with toltrazuril remained between 1 and 2 during the entire sampling period. In this study, treatment had obviously no effect on fecal consistency of the piglets infected with the Dutch isolate. The group Holl-20 showed the highest mean fecal score, the highest prevalence of diarrhea and most diarrhea days among the three groups. These parameters were also similar in groups HollCtrl and Holl-30, indicating complete lack of clinical efficacy of toltrazuril. Despite the limited data set available so far for Holland-I, this strain might be of low virulence since overall prevalences and days of diarrhea were low and a FS of 4 was not observed even once. However, inter-and intra-litter deviations cannot be excluded in this setting. Just as with oocyst excretion, the development and severity of diarrhea varies between litters and individuals $[48,52,53]$ and is also influenced by other factors [7].
Chapman [54] considered an Eimeria strain to be resistant if the weight gain of treated infected chicken did not differ significantly from that of untreated infected controls. In fact, treatment with the recommended or the elevated dose did not have a significant effect on body weight gains in the Dutch isolate, indicating resistance to toltrazuril. This finding is not surprising as the mean fecal score, which was negatively correlated with the individual weight gain, did not differ significantly between the control and treatment groups of isolate Holland-I. It has previously been shown that diarrhea is negatively correlated with the body weight gain in C. suis infections and that the application of toltrazuril significantly increases the weight gain of piglets compared to untreated infected controls [7, 17, 26, 40], although for the groups infected with Wien-I this could not be shown due to the small group size.

On grounds of the clinical picture observed during the study, it can be assumed that the bacterial agents identified by microbiological examination are facultative pathogenic subtypes regularly found in porcine intestinal flora $[55,56]$. This is underpinned by the fact that no sign of disease occurred in group Wien-20, despite the presence of the same bacteria as in all other groups. Jonach et al. [57] did not find statistical differences in the intestinal abundance of $E$. coli or $C$. perfringens when comparing piglets with and without diarrhea. This was confirmed by Ruiz et al. [58] who found similar prevalences in piglets with diarrhea and control piglets while frequencies of $C$. suis were significantly higher in diarrheic piglets.

To our knowledge, this study is the first to experimentally confirm toltrazuril resistance in a $C$. suis isolate. There are currently no satisfying treatment alternatives available $[20,23]$, underlining the need of new intervention strategies against porcine neonatal coccidiosis. Sulfonamides have been suggested against porcine coccidiosis but a short-term oral administration was shown to have an unsatisfying effect $[17,26]$. Only an injectable sulfonamide, repeatedly administered for 6 to 7 days, had an effect on parasite development and clinical outcome comparable to that of toltrazuril under experimental conditions [20]. Such a treatment may be considered as an alternative in cases of toltrazuril resistance, but it is labor-intensive and unsuited for routine treatment. Therefore, alternative control strategies to chemometaphylaxis are desirable [59].

Luckily, it seems that resistance in C. suis develops far slower than in avian coccidia. Vertommen et al. [60] described the development of resistance to Baycox ${ }^{\circ}$ against Eimeria on a broiler farm within four fattening periods. Nevertheless, the rise of further resistant $C$. suis isolates may just be a matter of time as the extensive use of a drug over a longer period of time will inevitably lead 
to decreased efficacy $[29,44]$. Currently, the sensitivity of $C$. suis isolates to toltrazuril can only be evaluated in vivo. A less laborious and faster in vitro assay, possibly employing the already established cell culture system [61], would be advantageous.

\section{Conclusions}

Toltrazuril resistant $C$. suis isolates are a potential threat to pig farming as no other effective and economically sustainable alternative treatment is available. All piglets infected with the field isolate of $C$. suis Holland-I showed appreciable levels of diarrhea and oocyst excretion unresponsive to treatment. Therefore, veterinarians and farmers should be aware of the possibility of resistance development with long-term application of toltrazuril in intensive piglet production systems. In the absence of vaccines and effective anticoccidial agents other than toltrazuril, routine fecal screening and periodical assessment of efficacy of toltrazuril must be considered essential for the sustainable control of cystoisosporosis. In cases of reduced efficacy optimized hygiene measures employing regular chemical disinfection with a cresol-based product must be enforced.

\section{Additional file}

Additional file 1: Table S1. Mean body weights and body weight gains in grams with standard deviations in brackets. SD: Study day. (DOCX $15 \mathrm{~kb}$ )

\section{Abbreviations}

AF: Autofluorescence; AUC: Area under the curve; BW: Body weight; dpi: Days post-infection; EU: European Union; FS: Fecal score; OpG: Oocysts per gram feces; SD: Study days

\section{Acknowledgements}

The authors are grateful to S. Rohrer, M. Lastufka and H. Dankovsky for their technical support and to A. Grätzl for helping in sample collection.

\section{Funding}

This study was partially funded by the University of Veterinary Medicine Vienna's Graduate School of Pig and Poultry Medicine and the Austrian Research Promotion Agency (project number 846007).

Availability of data and materials

All the datasets analyzed during this study are included within the article.

\section{Authors' contributions}

$A J, R J, A S, B R$ and $B F$ conceived and designed the study. BR maintained the strains of $C$. suis. AS, BF and BH performed the animal experiment. AS, BF and BR analyzed the samples. AS and BF drafted the manuscript. All authors read and approved the final manuscript.

\section{Ethics approval}

All procedures involving animals were approved by the Animal Ethics Committee of the University of Veterinary Medicine Vienna and the Austrian Federal Ministry of Science and Research according to the Austrian Animal protection law BMWF-68.205/0034-WF/N/3b/2016.

\section{Consent for publication}

Not applicable.

\section{Competing interests}

The authors declare that they have no competing interests.

\section{Publisher's Note}

Springer Nature remains neutral with regard to jurisdictional claims in published maps and institutional affiliations.

\section{Author details}

${ }^{1}$ Institute of Parasitology, Department of Pathobiology, University of Veterinary Medicine Vienna, Vienna, Austria. ${ }^{2}$ Boehringer Ingelheim, Alkmaar, The Netherlands.

Received: 18 April 2017 Accepted: 20 June 2017

Published online: 29 June 2017

References

1. Harleman $\mathrm{JH}$, Meyer RC. Isospora suis infection in piglets. A review Vet Q. 1983;5(4):178-85.

2. Stuart BP, Lindsay DS. Coccidiosis in swine. Vet Clin North Am Food Anim Pract. 1986:2(2):455-68.

3. Meyer C, Joachim A, Daugschies A. Occurrence of Isospora suis in larger piglet production units and on specialized piglet rearing farms. Vet Parasitol. 1999:82(4):277-84

4. Daugschies A, Imarom S, Ganter M, Bollwahn W. Prevalence of Eimeria spp. in sows at piglet-producing farms in Germany. J Vet Med B Infect Dis Vet Public Health. 2004:51(3):135-9.

5. Lindsay DS, Current WL, Taylor JR. Effects of experimentally induced Isospora suis infection on morbidity, mortality and weight gains in nursing pigs. Am J Vet Res. 1985;46(7):71511-2.

6. Lindsay DS, Current WL, Power TA. Enteric coccidial infections and coccidiosis in swine. Compend Contin Educ Vet. 1992;14:698-702.

7. Mundt HC, Joachim A, Becka M, Daugschies A. Isospora suis: an experimental model for mammalian intestinal coccidiosis. Parasitol Res. 2006;98(2):167-75

8. Aliaga-Leyton A, Webster E, Friendship R, Dewey C, Vilaca K, Peregrine AS. An observational study on the prevalence and impact of Isospora suis in suckling piglets in southwestern Ontario, and risk factors for shedding oocysts. Can Vet J. 2011;52(2):184-8.

9. Koudela B, Kučerová S. Immunity against Isospora suis in nursing piglets. Parasitol Res. 2000;86(10):861-3.

10. Shrestha A, Abd-Elfattah A, Freudenschuss B, Hinney B, Palmieri N, Ruttkowski B, et al. Cystoisospora suis - a model of mammalian cystoisosporosis. Front Vet Sci. 2015;2:68.

11. Torres A. Prevalence study of Isospora suis in Europe. In: $18^{\text {th }}$ International Pig Veterinary Society Congress. Hamburg; 2004

12. Driesen SJ, Carland PG, Fahy VA. Studies on preweaning piglet diarrhea. Aust Vet J. 1993;70(7):259-62.

13. Sanford SE, Josephson GK. Porcine neonatal coccidiosis. Can Vet J. 1981:22: 282-5.

14. Mundt HC, Cohnen A, Daugschies A, Joachim A, Prosl H, Schmäschke R, et al. Occurrence of Isospora suis in Germany, Switzerland and Austria. J Vet Med B Infect Dis Vet Public Health. 2005;52(2):93-7.

15. Mundt HC, Daugschies A, Joachim A. Increased awareness of piglet coccidiosis. Pig Progress. 2007;1:22-5.

16. Roepstorff A, Nilsson O, Oksanen A, Gjerde B, Richter SH, Örtenberg E, et al. Intestinal parasites in swine in the Nordic countries: prevalence and geographical distribution. Vet Parasitol. 1998;76(4):305-19.

17. Mundt HC, Mundt-Wüstenberg S, Daugschies A, Joachim A. Efficacy of various anticoccidials against experimental porcine neonatal isosporosis. Parasitol Res. 2007;100(2):401-11.

18. Haberkorn A. Bay Vi 9142, a new coccidiocidal drug and a new concept of prevention of coccidiosis. In: XVII World's Poultry Congress. Helsinki; 1984. 772-3.

19. Mehlhorn H, Greif G. Baycox. In: Mehlhorn H, editor. Encyclopedia of Parasitology. Berlin: Springer Berlin; 2016. p. 299-300.

20. Joachim A, Mundt HC. Efficacy of sulfonamides and Baycox ${ }^{\circledast}$ against Isospora suis in experimental infections of suckling piglets. Parasitol Res. 2011;109(6):1653-9.

21. Mundt HC. Baycox $5 \%$ an anticoccidial for the treatment of Isospora suis coccidiosis in piglets. In: $16^{\text {th }}$ International Pig Veterinary Society Congress. Melbourne; 2000. p. 80. 
22. Rypula K, Porowski M, Kaba J, Gorczykowski M, Deniz A. Effect of isosporiasis prevention with toltrazuril on long-term pig performance. Sci World J. 2012; 2012:486324.

23. Skampardonis V, Sotiraki S, Kostoulas P, Leontides L. Effect of toltrazuril treatment in nursing piglets naturally infected with Isospora suis. Vet Parasitol. 2010;172(1-2):46-52.

24. Kreiner T, Worliczek HL, Tichy A, Joachim A. Influence of toltrazuril treatment on parasitological parameters and health performance of piglets in the field-an Austrian experience. Vet Parasitol. 2011;183(1-2):14-20.

25. Mengel H, Krüger M, Krüger MU, Westphal B, Swidsinski A, Schwarz S, et al. Necrotic enteritis due to simultaneous infection with Isospora suis and Clostridia in newborn piglets and its prevention by early treatment with toltrazuril. Parasitol Res. 2012;110(4):1347-55.

26. Scala A, Demontis F, Varcasia A, Pipia A, Poglayen G, Ferrari N, et al. Toltrazuril and sulphonamide treatment against naturally Isospora suis infected suckling piglets: is there an actual profit? Vet Parasitol. 2009;163(4):362-5.

27. Pommier P, Keita A, Wessel-Robert S, Dellac B, Mundt HC. Efficacy of toltrazuril in the prevention and the treatment of suckling piglets coccidiosis: results of two field trials. Rev Med Vet. 2003;1:41-6.

28. Boulanger A, De Jesus A, Araujo D, Sogbe E, Utrera V, Herrera D, et al. Efficacy of toltrazuril (Baycox) in the prevention of coccidial diarrhea in piglets in Venezuela. In: $13^{\text {th }}$ International Pig Veterinary Society Congress. Bangkok; 1994. p. 258.

29. Chapman HD. Biochemical, genetic and applied aspects of drug resistance in Eimeria parasites of the fowl. Avian Pathol. 1997;26(2):221-44.

30. Stephan B, Rommel M, Daugschies A, Haberkorn A. Studies of resistance to anticoccidials in Eimeria field isolates and pure Eimeria strains. Vet Parasitol. 1997;69(1):19-29.

31. Chapman HD, Jeffers TK. Vaccination of chickens against coccidiosis ameliorates drug resistance in commercial poultry production. Int J Parasitol Drugs Drug Resist. 2014;4(3):214-7.

32. Vítovec J, Koudela B. Pathology of natural isosporosis in nursing piglets. Folia Parasitol (Praha). 1987;34(3):199-204.

33. Vítovec J, Koudela B. Double alteration of the small intestine in conventional and gnotobiotic piglets experimentally infected with the coccidium Isospora suis (Apicomplexa, Eimeriidae). Folia Parasitol (Praha). 1990;37(1):21-3.

34. Chapman HD. E. tenella, E. acervulina and E. maxima: studies on the development of resistance to diclazuril and other anticoccidial drugs in the chicken. Parasitology. 1989;99(Pt 2):189-92.

35. Kawazoe U, Fabio JD. Resistance to diclazuril in field isolates of Eimeria species obtained from commercial broiler flocks in Brazil. Avian Pathol. 1994; 23(2):305-11.

36. Peek HW, Landman WJ. Resistance to anticoccidial drugs of Dutch avian Eimeria spp. field isolates originating from 1996, 1999 and 2001. Avian Pathol. 2003;32(4):391-401.

37. Daugschies A, Bialek R, Joachim A, Mundt HC. Autofluorescence microscopy for the detection of nematode eggs and protozoa, in particular Isospora suis, in swine faeces. Parasitol Res. 2001;87(5):409-12.

38. Chapman HD. Drug resistance in avian coccidia (a review). Vet Parasitol. 1984;15(1):11-27.

39. Shirley MW, Smith AL, Blake DP. Challenges in the successful control of the avian coccidia. Vaccine. 2007;25(30):5540-7.

40. Maes D, Vyt P, Rabaeys P, Gevaert D. Effects of toltrazuril on the growth of piglets in herds without clinical isosporosis. Vet J. 2007;173(1):197-9.

41. Mundt HC, Daugschies A, Wüstenberg S, Zimmermann M. Studies on the efficacy of toltrazuril, diclazuril and sulphadimidine against artificial infections with Isospora suis in piglets. Parasitol Res. 2003;90(3):S160-S62.

42. Bach U, Kalthoff V, Mundt HC, Popp A, Rinke M, Daugschies A, et al. Parasitological and morphological findings in porcine isosporosis after treatment with symmetrical triazintriones. Parasitol Res. 2003;91(1):27-33.

43. Bloland PB. Drug resistance in malaria. Geneva: World Health Organization; 2001. p. 1-27.

44. Peek HW, Landman WJ. Coccidiosis in poultry: anticoccidial products, vaccines and other prevention strategies. Vet Q. 2011;31(3):143-61.

45. Harleman JH, Meyer RC. Life cycle of Isospora suis in gnotobiotic and conventionalized piglets. Vet Parasitol. 1984;17:27-9.

46. Vítovec J, Koudela B. Reduced pre-patent period in experimental onfection of piglets with the coccidium Isospora suis. Folia Parasitol (Praha). 1987;34(1):10.

47. Chapman HD. Evaluation of the efficacy of anticoccidial drugs against Eimeria species in the fowl. Int J Parasitol. 1998;28(7):1141-4.
48. Martineau GP, del Castillo J. Epidemiological, clinical and control investigations on field porcine coccidiosis: clinical, epidemiological and parasitological paradigms? Parasitol Res. 2000;86(10):834-7.

49. Joachim A, Schwarz L, Hinney B, Ruttkowski B, Vogl C, Mundt HC. Which factors influence the outcome of experimental infection with Cystoisospora suis? Parasitol Res. 2014;113(5):1863-73.

50. Worliczek HL, Gerner W, Joachim A, Mundt HC, Saalmueller A. Porcine coccidiosis - investigations on the cellular immune response against Isospora suis. Parasitol Res. 2009;105:S151-5.

51. McQorist S, Blunt R, Elsheikha H, Alujas AM, Ocak M, Deniz A. Evaluation of efficacy of oral toltrazuril (Baycox $5 \%{ }^{\circledR}$ ) for the improvement of postweaning gut health in pigs. Pig J. 2010;63(12):72-9.

52. Sotiraki S, Roepstorff A, Nielsen JP, Maddox-Hyttel C, Enoe C, Boes J, et al. Population dynamics and intra-litter transmission patterns of Isospora suis in suckling piglets under on-farm conditions. Parasitology. 2008;135(3):395-405.

53. Worliczek HL, Buggelsheim M, Alexandrowicz R, Witter K, Schmidt P, Gerner W, et al. Changes in lymphocyte populations in suckling piglets during primary infections with Isospora suis. Parasite Immunol. 2010;32(4):232-44.

54. Chapman HD. Studies on the sensitivity of field isolates of Eimeria maxima to combinations of anticoccidial drugs. Avian Pathol. 1980;9(1):67-6.

55. Niestrath M, Takla M, Joachim A, Daugschies A. The role of Isospora suis as a pathogen in conventional piglet production in Germany. J Vet Med B Infect Dis Vet Public Health. 2002;49(4):176-80.

56. Songer JG, Uzal FA. Clostridial enteric infections in pigs. J Vet Diagn Investig. 2005;17(6):528-36.

57. Jonach B, Boye M, Stockmarr A, Jensen TK. Fluorescence in situ hybridization investigation of potentially pathogenic bacteria involved in neonatal porcine diarrhea. BMC Vet Res. 2014;10(1):68.

58. Ruiz VLA, Bersano JG, Carvalho AF, Catroxo MHB, Chiebao DP, Gregori F, et al. Case-control study of pathogens involved in piglet diarrhea. BMC Res Notes. 2016:9:22.

59. Joachim A. Vaccination against parasites - status quo and the way forward. PHM. 2016:2(1):30.

60. Vertommen $\mathrm{MH}$, Peek HW, van der Laan A. Efficacy of toltrazuril in broilers and development of a laboratory model for sensitivity testing of Eimeria field isolates. Vet Q. 1990;12(3):183-92.

61. Worliczek HL, Ruttkowski B, Schwarz L, Witter K, Tschulenk W, Joachim A. Isospora suis in an epithelial cell culture system - an in vitro model for sexual development in coccidia. PLoS One. 2013;8(7):e69797-e97.

\section{Submit your next manuscript to BioMed Central and we will help you at every step:}

- We accept pre-submission inquiries

- Our selector tool helps you to find the most relevant journal

- We provide round the clock customer support

- Convenient online submission

- Thorough peer review

- Inclusion in PubMed and all major indexing services

- Maximum visibility for your research

Submit your manuscript at www.biomedcentral.com/submit
Biomed Central 